\title{
NOVAS RELAÇÕES ENTRE ESTADO E SOCIEDADE CIVIL NO ÂMBITO DA HABITAÇÃO: um estudo de caso*
}

\section{Adriana Andrela Camponez}

\author{
Especialista em Sociologia e Sociologia da Educação.
}

\begin{abstract}
Observa-se no cenário brasileiro dos anos 90 a redefinição das relações entre Estado e sociedade civil no encaminhamento das políticas públicas. O Projeto Casa Fácil - Convênio de Moradia Popular é um exemplo dessa nova perspectiva. Desenvolvido pelo Clube de Engenharia e Arquitetura de Londrina, é uma forma alternativa de política pública nãogovernamental no campo da habitação. Este artigo analisa a experiência do Projeto Casa Fácil como exemplo desta nova relação, enfatizando os interesses que permeiam a relação de parceria entre a prefeitura local e o Clube de Engenharia no atendimento das demandas populares do setor habitacional.
\end{abstract}

Palavras-chave: política habitacional; Estado; sociedade civil.

\section{INTRODUÇÃO}

A redefinição dos espaços de atuação do Estado $^{1}$ e da sociedade civil no âmbito da política habitacional no cenário dos anos 90 é o tema deste artigo, que tem por objetivo analisar uma experiência de política não-governamental realizada por uma associação privada, o Clube de Engenharia e Arquitetura de Londrina.

No entanto, é necessário esclarecer que a discussão sobre os papéis do Estado e da sociedade civil, no que tange a essa questão, somente servirá como pano de fundo para a análise aqui proposta.

Desde o início da década, uma nova concepção de sociedade civil vem se delineando e desempenhando um papel de reivindicação de direitos e espaços de participação social, uma vez que reconhece a existência de uma lacuna entre Estado e mercado no campo das políticas públicas.

Esta nova relação desenvolve-se no contexto atual, marcado pela era da globalização que altera os processos produtivos, influenciando também as articulações entre o público e o privado.

Segundo GOHN (1995), tais transformações resultaram na potencialização de uma esfera (ou subesfera) entre $o$ público e o privado - o público não-estatal - e no surgimento de uma articulação dessas duas esferas, dada pelas políticas de parceria.

Diferentes redes de relações são geradas pelas ações coletivas, o que denota uma sociedade civil renovada. Como exemplo, pode-se citar a Campanha da Ação e Cidadania contra a Fome e a Miséria, liderada pelo sociólogo Herbert de Souza (o Betinho), lançada no ano de 1993.

Nota-se, dessa forma, o surgimento de duas grandes tendências: a primeira, o crescimento das organizações nãogovernamentais (ONGs), e, a mais importante para a discussão que se pretende fazer aqui, as políticas de parcerias implementadas pelo poder público, particularmente na esfera municipal.

Essas mudanças também podem ser explicadas a partir da crise econômica do sistema capitalista e da crise fiscal do Estado, ocorridas no final dos anos 70, que trouxeram como consequiência a manutenção do padrão de financiamento público do Estado de Bem-Estar Social (Welfare State) nos países desenvolvidos, situação que se agravou nos países onde o Estado de Bem-Estar sequer havia se consolidado.

A ineficácia das ações estatais diante desses desafios aponta para uma sociedade civil que deixa de ser mero objeto na história das políticas sociais para participar e contribuir na solução dos problemas emergentes da sociedade. $\mathrm{Se}$

\footnotetext{
* O texto é uma adaptação da monografia intitulada Política habitacional: as novas relações entre Estado e sociedade civil, apresentada como trabalho de conclusão do curso de Especialização em Sociologia e Sociologia da Educação, da UEL, em novembro de 1996, sob orientação do professor Ronaldo Baltar.
} 
antes predominavam Estado e mercado na provisão das políticas sociais, agora há uma politização do espaço público, ou seja, a sociedade civil passa a ter uma presença política mais marcante.

É nesse contexto que a análise das novas relações estabelecidas entre Estado e sociedade civil ganha relevância, e o Projeto Casa Fácil, sendo um exemplo dessas relações, justifica um estudo a respeito de sua contribuição na problemática habitacional.

Este artigo obedece à seguinte estrutura: o primeiro item resgata historicamente a política habitacional brasileira; o segundo, expõe a estrutura do Projeto Casa Fácil; e, o terceiro, traz a análise do desenvolvimento do projeto e os resultados alcançados por ele.

\section{A POLÍTICA HABITACIONAL BRASILEIRA}

A crise da habitação não é um problema contemporâneo e nem do proletariado moderno. ENGELS (1979), ao analisar as grandes cidades e a questão da moradia na Inglaterra, mostrou que as classes oprimidas sempre sofreram com a questão. Essa situação também não foi diferente para o trabalhador brasileiro de baixa renda, que, historicamente, só conheceu condições precárias de moradia.

No Brasil, o espaço destinado à habitação popular foi marcado por diversas modalidades habitacionais: senzala, favela, cortiço, vila operária, loteamento clandestino e conjunto habitacional.

O perfil atual dos problemas habitacionais começou a ser moldado a partir da década de 30 , quando o processo de desenvolvimento da industrialização no país estimulou o êxodo rural, gerando um excedente populacional que contribuiu para o crescimento desordenado das grandes cidades.

Naquele momento a oferta de emprego era menor do que a de mão-de-obra; a escassa (ou nula) remuneração não propiciava a satisfação das necessidades de reprodução da força de trabalho. A população carente passou, então, a ocupar terras de propriedade de outros, dando origem às favelas. Embora surgidas no final do século passado, somente a partir da década de 30 as favelas tornam-se marcantes na paisagem urbana. (VALADARES,1983, p.22)

Com as vilas operárias acontece o mesmo. Devido ao interesse das indústrias em alojar sua mão-de-obra de forma ordenada e a baixo custo, várias vilas foram construídas naquele período, sem que resolvessem, no entanto, as necessidades dos operários. Os trabalhadores que não eram instalados em vilas operárias alojavam-se em cortiços, por serem próximos dos locais de trabalho e baratos.

Com a intensificação do crescimento industrial formou-se um excedente de força de trabalho na cidade, isto é, um exército de reserva, tornando-se desnecessária a fixação do trabalhador na empresa; "o industrial só vai se preocupar com o problema habitacional do operário antes de se constituir, na cidade, um exército industrial de reserva, após o que deixa de se preocupar com o problema da habitação". (COGEP apud BLAY, 1985, p.25)
Aliado à formação do exército de reserva, houve um crescimento populacional que ampliou a pressão sobre a oferta de habitação popular, o que favoreceu, de certa forma, a valorização dos lotes urbanos, inviabilizando as vilas operárias.

Com o desaparecimento dessas vilas, a questão da moradia passa a ser resolvida pelas relações econômicas no mercado imobiliário. Dessa maneira, surgem no cenário urbano as periferias, que são aglomerados carentes de infraestrutura onde reside a classe trabalhadora de baixa renda.

Com o crescimento das grandes cidades, o valor do solo urbano atinge níveis muito altos e o trabalhador é afastado dos centros equipados. Assim, o valor do solo urbano vai determinar a distribuição espacial da população na cidade. Favelas, cortiços, loteamentos clandestinos, entre outras formas de moradia, abrigaram e continuam abrigando a classe trabalhadora, cujas condições de alojamento expressam a precariedade dos seus salários.

O quadro habitacional delineado ao longo das últimas décadas é consequiência da tardia preocupação do poder público em ordenar o uso do solo urbano. As primeiras iniciativas nesse sentido ocorrem quando o traçado urbano já está em grande parte constituído.

A ação governamental restringiu-se quase sempre a seguir os núcleos de ocupação criados pelo setor privado. Dessa forma, os investimentos públicos se colocaram a serviço da dinâmica de especulação do sistema imobiliário.

Esse panorama procurou mostrar que a habitação popular passou por várias formas e continua a se desenvolver num processo permanente de adaptação e mudanças relacionadas às condições históricas do sistema capitalista, concomitante às ações governamentais estabelecidas a partir das políticas públicas.

\subsection{Perspectiva histórica da política habita- cional no Brasil}

É a partir da década de 40 que o Estado começa a sistematizar sua ação na provisão da habitação popular no Brasil. Em maio de 1946, no governo populista de Gaspar Dutra surge o primeiro organismo nacional para a construção de residências populares, a Fundação da Casa Popular (FCP) (instituída pelo decreto lei $\mathrm{n}^{2}$ 9.218). Com a implementação de tal política, o governo Dutra procurava legitimar-se junto aos trabalhadores através da casa própria. (PERUZZO,1984, p.34)

Fatores importantes como a insatisfação popular, a ascensão do Partido Comunista e a concorrência do capital estrangeiro contribuíram para a criação da FCP, que, dentre outros interesses, tinha por objetivo os controles individual e social dos adquirentes da casa própria. Assim,

"Previa-se punição, com perda da casa, para os compradores que, por seu procedimento, vierem a tornar-se nocivos à ordem ou a moral do núcleo residencial, ou criarem embaraço à sua administração (...) ou que promover agitação de qualquer natureza no conjunto ou permitir que dependente seu o 
faça (...) ou aquele que se negar a receber, em seu imóvel, funcionários do serviço de assistência social da FCP (...) a prestar-lhe informações solicitadas. Também punido com a perda da casa é o adquirente que não destinar o prédio exclusivamente para sua moradia e da família, ou utilizá-la em atividade de caráter religioso, político, esportivo, recreativo ou outras inconciliáveis com a finalidade a que é destinado o imóvel". (AZEVEDO \& ANDRADE, apud PERUZZO, 1984, p.34)

As prestações da casa eram fixas, isto é, não sofriam correção monetária, o que gerava a descapitalização das entidades promotoras diante da inflação progressiva. Com isso, a proposta de subsídio total tornou-se inviável para a política habitacional populista, que não tinha como conciliar a política de retorno de investimento com a imagem paternalista do Estado. A FCP foi extinta em 1964, com o número de 16.964 unidades produzidas no período de 1946 a 1960 .

O Banco Nacional de Habitação (BNH) e o Sistema Financeiro da Habitação (SFH) foram criados pela lei $\mathrm{n}^{0}$ 4.380 de 21 de agosto de 1964 , cinco meses após o golpe de 64. Produtos da ditadura, representaram durante o período do regime autoritário a política nacional de habitação, constituindo-se um poderoso órgão governamental, encarregado de solucionar a crise da habitação no país. Diante desse quadro percebe-se que, "Alterando a ótica clientelista do modelo da política habitacional do populismo, o regime militar estabeleceu um sistema baseado num modelo empresarial para sua política habitacional". O que não significou o fim da prática populista. (MNLM, 1994, p.6)

A solução do problema da moradia nunca foi a prioridade do $\mathrm{BNH}$, cuja principal finalidade era a retomada do crescimento de vários setores econômicos. A grande maioria dos críticos da política habitacional brasileira considera que o objetivo real do BNH era usar o dinheiro da classe trabalhadora para promover a acumulação do capital.

Mário Trindade e Maurício Schulmam, presidentes do BNH, deixam claro em seus discursos os verdadeiros objetivos deste órgão:

"No quadro de desenvolvimento urbano brasileiro, o problema mais importante não era a casa, era a abertura de oportunidades de emprego para absorvermos as massas de trabalhadores semi-especializados, de oportunidades para mobilizarmos os escritórios de engenharia, de planejamento, de projetos de arquitetura e dar trabalho às firmas de construção civil e à industria da construção, forças paralisadas na economia brasileira". (TRINDADE apud AZEVEDO \& ANDRADE apud PERUZZO,1984, p.42)

"Acelerar a atividade da construção civil, dada sua elevada participação na geração de rendas internas por pouco pressionar a balança comercial e pela capacidade de ocupação de mão-de-obra. Destinava-se também a criar condições que propiciassem uma ampliação na oferta de novas moradias, com priori- dade de atendimento às famílias de menor renda". (SCHULMAN apud VERAS apud PERUZZO, 1984, p.42)

A partir dos discursos oficiais observa-se que os interesses estavam mais voltados à criação de condições para a reprodução do capital do que à oferta de moradias para a população de baixa renda.

Para estimular a construção civil, reserva do capital nacional, o Estado cria mecanismos que se contrapõem à depreciação dos investimentos. Um exemplo desses mecanismos é a instituição da correção monetária, que permitiu fazer a constante atualização do valor da poupança e dos investimentos e dos saldos devedores dos créditos hipotecários. (PERUZZO, 1984, p.44)

Segundo Flávio Villaça, o BNH traz uma característica inovadora, por não depender de recursos do governo. $\mathrm{O}$ banco usava recursos exclusivamente privados, captados através de dois mecanismos de poupança instituídos: a poupança voluntária (a das cadernetas de poupança do Sistema Brasileiro de Poupança e Empréstimo-SBPE) e a poupança compulsória (representada pelos recursos do Fundo de Garantia por Tempo de Serviço-FGTS). O BNH entregava esses recursos ao setor produtivo (a construção civil) e ao setor especulativo (da promoção imobiliária) via intermediários (agentes financeiros), incumbidos de promover a acumulação através da produção e venda das próprias moradias. Esses setores do capital ficavam com as rendas e lucros auferidos. Ao completar este ciclo, e depois de acumulada uma parte do capital, os recursos eram devolvidos aos proprietários iniciais. (VILLAÇA, 1986,p.83)

"O Sistema Financeiro da Habitação é um mecanismo através do qual o Estado desempenha a função de transferência de renda das classes subordinadas para outras classes, visto que a fonte dos recursos originados no FGTS é compulsória e socializada, dela participam todos os assalariados. Porém, as aplicações desses recursos são canalizadas em proporção maior para os setores que concorrem com a contribuição menor". (PERUZZO, 1984, p.47)

O FGTS impõe um recolhimento obrigatório de $8 \%$ da folha de pagamento de todos os trabalhadores brasileiros. Esse dinheiro, acrescido das cadernetas de poupança, deveria ser usado em benefício do trabalhador desprovido de moradia. No entanto, foi usado em construções grandiosas, como a hidrelétrica de Itaipu e usinas nucleares, fugindo totalmente da proposta inicial do $\mathrm{BNH}$.

De acordo com a Plataforma Nacional da Habitação Popular do Movimento Nacional de Luta por Moradia (MNLM), o BNH passou por diversas fases. Na primeira, compreendida entre 1960 e 1967, buscou estruturar-se através da articulação institucional com o setor privado, ao qual caberiam as funções de executor da política habitacional.

Na segunda fase, que vai de 1967 a 1971, foram ampliados seus recursos financeiros (FGTS e Caderneta de Poupança) e aprimorados seus instrumentos operacionais: SBPE e Companhias de Habitação (COHABs). 
A terceira fase, de 1971 a 1979 , marca a transformação do BNH em um banco de segunda linha, transferindo aos seus agentes os recursos financeiros e a responsabilidade de suas cobranças, eximindo-se das críticas e da pressão dos mutuários.

$\mathrm{O} \mathrm{BNH}$, ainda na década de 70 , passou a direcionar seus recursos na produção de obras de infra-estrutura urbana (implantação do sistema de abastecimento de água e esgoto sanitário do sistema viário, da rede de energia elétrica, de transporte e de serviços públicos, dentre outras). Com isso aumentou suas condições de desenvolver uma política voltada para as obras urbanas, podendo diversificar seus programas. (MARICATO, 1987, p.33)

Dentre os programas de desenvolvimento urbano foi criado o Projeto Comunidades Urbanas para Recuperação Acelerada (CURA), que propunha a correção das distorções da especulação imobiliária, bem como o impulso dos investimentos urbanos. O programa abriu definitivamente a possibilidade de o BNH entrar no âmago do jogo imobiliário, uma vez que a localização do imóvel em área beneficiada por investimentos públicos favorece o aumento dos preços dos terrenos. (idem, p.35)

É significativo o aumento feito pelo BNH em programas de desenvolvimento urbano, o qual reflete seus novos interesses. Em 1971, o investimento destinado à habitação era de $75 \%$, enquanto que apenas $4 \%$ eram aplicados no desenvolvimento urbano. Em 1976 este quadro se altera: os recursos para habitação diminuíram, enquanto que os outros aumentaram em $33 \%$ em relação ao número do início da década.

Em 1973 é criado o programa Fundos Regionais de Desenvolvimento Urbano. Em 1974 são criados o Financiamento para Urbanização, o Financiamento para Sistemas Ferroviários de Transporte Urbano de Passageiros, o Financiamento para o Planejamento Urbano e, o mais expressivo dos investimentos, o Plano Nacional de Habitação Popular, que tinha por objetivo corrigir as experiências anteriores do $\mathrm{BNH}$ no que tange à habitação popular. (idem, p.42)

A partir de 1977, constatando que as COHABs não estavam alcançando a população-alvo (de renda até três salários mínimos), o BNH implantou novos programas na tentativa de atender esta demanda.

A quarta fase do BNH vai de 1979 até sua extinção, em 1985. Nesse período agravam-se seus problemas financeiros, também em consequiência da crise econômica do país.

Em 1977 surgiram vários programas, como o de Financiamento da Construção ou Melhoria da Habitação de Interesse Social; em maio de 1978 há a reformulação do Programa de Lotes Urbanizados; em 1979 é criado o Programa de Erradicação da Subhabitação; e, em 1980, tem início o Programa Nacional de Habitação para o Trabalhador Sindicalizado. (idem, p.54)

O BNH, além de não conseguir melhorar as condições de moradia da população na área urbana no período que esteve em vigor, aumentou a precariedade habitacional no país. Segundo Maricato, "apesar do esforço de chegar às camadas mais pobres da população, bastante propagandeado pelo $\mathrm{BNH}$, ele não logrou sequer atenuar o intenso processo de favelização e de queda na qualidade habitacional que foi flagrante nas grandes cidades brasileiras. Os números e empreendimentos apresentados podem ser considerados positivos em si mesmos, mas nunca se relacionados ao oceano de demanda habitacional no Brasil". (idem, p.56)

Todo um cenário desfavorável se formou em torno do $\mathrm{BNH}$, agravado pela sua própria incapacidade de autofinanciamento, o que ocasionou a extinção do banco em 1985, passando, assim, para a Caixa Econômica Federal (CEF) todas as suas atribuições.

Embora a CEF tenha ficado responsável pelo controle de recursos da política habitacional, que são as cadernetas de poupança e o FGTS, isso não implicou em nenhuma mudança relevante no quadro da política habitacional do país. A população que ganha até três salários mínimos, representando 70\% da população urbana do país, continua esquecida. Os financiamentos são nivelados a partir de rendimentos superiores.

“A extinção do Ministério do Desenvolvimento Urbano, no Governo Collor, passando a atribuição da política habitacional para o Ministério da Ação Social, revela que a política pública para este setor regrediu para o assistencialismo". (MNLM, 1994, p.10)

Através do Programa de Ação Imediata para Habitação, gerido pelo Ministério da Ação Social no governo Collor, liberou-se a quantia de 3 bilhões de dólares para a construção de 500 mil casas populares. A partir de dados oficiais, sabe-se que foram construídas 495 mil unidades, sendo que 293 mil casas não foram comercializadas e 67 mil unidades continuam paradas. (idem, p.12)

Devido à carência de equipamentos nos loteamentos urbanos destinados à construção dos conjuntos habitacionais, resultado do descaso do poder público, as prestações tomaram-se muito elevadas, aumentando os índices de inadimplência.

Revelam-se, assim, as falhas da política habitacional brasileira, que, em aproximadamente sessenta anos de atuação, desde sua primeira ação oficial, não conseguiu diminuir efetivamente o problema habitacional dos trabalhadores.

\subsection{Novos caminhos da política habitacio- nal: o envolvimento da sociedade civil or- ganizada}

Em novembro de 1991, movimentos sociais por moradia apresentaram proposta de lei para a criação do Fundo Nacional de Moradia Popular. Este é o primeiro projeto de lei de iniciativa popular da história brasileira. Com ele foi possível a articulação da sociedade civil na discussão e na viabilização de ações que contribuíram na solução da crise habitacional no país.

Diante da ineficiência do governo federal, tem-se assistido atualmente, no campo das políticas públicas, à busca de alternativas de produção e distribuição de bens e serviços sociais até então desenvolvidas e executadas pelos dois únicos pólos possíveis: Estado e mercado.

A partir dos anos 80 , grande parte das inovações na política social, como aponta DRAIBE (1989), é resultado 
das mudanças nos processos sociais que tendem a alterar as relações entre o público e o privado, indicando uma tendência à transformação dos modos de produzir e distribuir os bens e serviços sociais. Este novo espaço passa a ser ocupado pela sociedade civil através de diferentes formas de solidariedade social.

Vários são os meios utilizados, como mutirões, autoconstruções, experiências de ajuda mútua, formas comunitárias, cooperativas diversas e sistemas de parceria, dentre outros, que, não só no Brasil, mas também em outros países, têm apresentado a participação dos próprios beneficiários e de organizações voluntárias não-governamentais no encaminhamento das políticas sociais.

Considerando o questionamento das formas clássicas da relação Estado/sociedade civil, um dos pontos centrais desse debate aparece na articulação entre o setor público e o setor privado ${ }^{2}$ na provisão de equipamentos e serviços coletivos, envolvendo, de um lado, a questão das atribuições do Estado, e, de outro, a participação do setor privado nessa provisão. (FARAH, 1990, p.11)

De modo geral, as considerações acerca das novas atribuições do Estado apontam propostas inovadoras de encaminhamento das políticas sociais, passando, também, por novas formas de articulação entre o público e o privado.

Nesse sentido, a sociedade civil tem atuado no processo de definição e gestão dessas políticas, promovendo mudanças e estimulando a ampliação de práticas descentralizadoras.

Como se sabe, a trajetória da política habitacional no Brasil apresenta características que se constituem entraves à sua operacionalização, destacando-se, dentre elas, a ineficiência, a demora na alocação de recursos em razão do burocratismo, o distanciamento do usuário por parte de formuladores e executores e a ausência de mecanismos de avaliação e controle dos programas sociais.

A partir da Nova República, promessas de reformas administrativas no funcionamento das políticas públicas foram acenadas pelo governo. A Constituição de 1988, em princípios gerais, acolheu algumas mudanças de ordem estrutural, como, por exemplo, a descentralização dos serviços sociais, com ênfase na municipalização e na integração dos serviços sociais frente às clientelas e no aumento da participação popular na implementação dos programas.

É nesse contexto que vários dispositivos de descentralização do poder são definidos. Do ponto de vista das políticas públicas, amplia-se a competência legislativa do município, atribuindo-lhe responsabilidades. "A novidade é dotar os municípios de recursos tributários, transformandoos em esfera autônoma de governo submetida a uma obrigação constitucional específica: a de fazer política social". (SERRA apud CASTRO, 1991, p.84) Além disso, a participação da sociedade local aparece como diretriz fundamental para o funcionamento mais autônomo e eficaz do município.

A democratização na provisão das políticas sociais exigiria maior integração entre Estado e sociedade civil no nível local, processo que se fortaleceria através da produção de serviços sociais financiados pelo Estado mas geridos por associações, corporações privadas não-lucrativas e ONGs, objetivando democratizar as relações sociais e as formas participativas cidadãs.

Como vimos anteriormente, as políticas sociais, em particular a política habitacional, enquanto espaço de atuação do Estado, só podem ser entendidas no contexto da estrutura capitalista e no movimento histórico das transformações sociais dessa mesma estrutura.

Desse modo, as funções do Estado variam historicamente de intensidade, de acordo com o estágio em que se encontra a relação entre as forças produtivas e as relações de produção.

Diante do processo da reestruturação da economia mundial na década de 80 , e das transformações no modo de regulação e acumulação das economias nacionais, mudanças estruturais entre Estado e mercado têm se delineado na provisão das políticas públicas.

Considerando esta perspectiva, pretende-se descrever e analisar como vem se definindo os espaços de atuação da sociedade civil organizada, que, através de várias formas alternativas, tem contribuído no encaminhamento das políticas habitacionais, redefinindo, assim, suas relações com o Estado.

Um exemplo dessa relação é o Projeto Casa Fácil, experiência pioneira no Estado do Paraná, que contribui para o atendimento da demanda da política habitacional.

Serão feitas a seguir a descrição e a análise do seu desenvolvimento, bem como do papel que representa nesse novo contexto, no qual a sociedade civil passa a ter uma participação mais ativa na resolução dos problemas sociais.

\section{O PROJETO CASA FÁCIL}

\subsection{Histórico}

Idealizado há trinta anos pelo Conselho Regional de Engenharia, Arquitetura e Agronomia do Estado do Paraná (CREA-PR) e administrado pelas parcerias entre associações de engenheiros e arquitetos, prefeituras municipais e universidades, o Projeto Casa Fácil vem beneficiando ao longo dos anos um total de 330 municípios paranaenses.

Em 1966, o CREA-PR começa a atuar como colaborador na questão habitacional através do Ato $\mathrm{n}^{\mathrm{Q}}$ 21/66. (CREA-PR, 1995)

"Partindo-se da constatação de que quem ganha até três salários mínimos tem dificuldade em contratar um profissional da engenharia ou da arquitetura para projetar e assumir a responsabilidade técnica de uma residência, por menor que seja, e que, em vista disso, a grande maioria das casas populares - mesmo as situadas em áreas urbanas dotadas de toda infra-estrutura - é composta de obras clandestinas, o Projeto Casa Fácil chega para corrigir essa distorção”. (idem, p.5)

Segundo o manual informativo do Projeto Casa Fácil, elaborado pelo CREA-PR, os benefícios do projeto ficam assim definidos. (idem, p.5-6): 
Para as famílias:

- Terão projetos gratuitos de até $70 \mathrm{~m}^{2}$, ou conforme metragem definida pela Associação.

- Receberão toda orientação técnica necessária.

- Com a ART isenta de taxas, poderão obter o alvará e o laudo de vistoria de conclusão de obras junto à Prefeitura e o Habite-se junto à Secretaria de Obras. - Poderão matricular a obra junto ao IAPAS, que também concede isenção de taxas para moradias de padrão popular até $70 \mathrm{~m}^{2}$.

- Poderão averbar a moradia no Cartório de Registro de Imóveis, garantindo a sua legítima propriedade e seu valor comercial.

- Terão a garantia de uma edificação segura, econômica e de melhor qualidade.

\section{Para as Prefeituras:}

- Cada moradia popular construída sob os auspícios do Projeto, diminuirá o rol das edificações clandestinas e aumentará o cadastro técnico municipal.

- Os engenheiros civis e arquitetos das Prefeituras ficam liberados de responder civilmente pela construção nos cinco anos exigidos pela lei, já que nesses casos especiais a responsabilidade está sendo assumida pelo proprietário.

- Os municípios que firmarem o convênio de Moradia Popular terão facilidades no ato de regularização das obras integrantes do Projeto.

- O Projeto é um aliado importante dos programas habitacionais das Prefeituras.

\section{Para as entidades de classe:}

- As Associações de Engenheiros e Arquitetos passam a ter presença mais atuante junto à comunidade, fortalecendo sua imagem de prestadora de serviços, uma vez que estarão à disposição dos interessados para a necessária orientação técnica durante a construção da obra.

- Seus associados ficam também liberados da responsabilidade técnica e civil.

\section{Para as Universidades:}

- A par de prestarem à comunidade um serviço de alcance social permitem que seus formandos de Engenharia e Arquitetura, na execução dos projetos, orçamentos e memorial técnico, recebem em forma de estágio custeado pelo CREA-PR.

A inspeção do projeto nos municípios é feita pelas entidades de classe, de forma regionalizada, através de 28 inspetorias localizadas nas seguintes cidades: Londrina, Cascavel, Toledo, Foz do Iguaçu, Marechal Cândido Rondon, Curitiba, São José dos Pinhais, Paranaguá, Rio Negro, Arapongas, Jacarezinho, Santo Antônio da Platina, Cornélio Procópio, Bandeirantes, Maringá, Apucarana, Umuarama, Paranavaí, Campo Mourão, Cianorte, Pato Branco, Francisco Beltrão, Laranjeiras do Sul, Palmas, Realeza, União da Vitória, Ponta Grossa, Irati, Telêmaco Borba, Castro e Guarapuava.

\subsection{Implantação do Projeto Casa Fácil em Londrina}

O Projeto Casa Fácil surge em Londrina no dia 27 de abril de 1990, através do Convênio de Prestação de Serviços Técnicos para Elaboração de Projeto e Orientação à Construção e Reforma de Moradia Popular, mas começa a atender efetivamente em Londrina no mês de julho, como mostra a seguinte reportagem do jornal Folha de Londrina:

\begin{abstract}
“A construção de moradias populares em Londrina vai tornar-se mais simples a partir da próxima quarta-feira, quanto começa a vigorar o Programa Casa Fácil. Através de um Convênio entre Prefeitura, Universidade de Londrina, Clube de Engenharia e Conselho Regional de Engenharia e Arquitetura (CREA), a população de baixa renda poderá contar com assistência técnica para construção de casas com até $70 \mathrm{~m}^{2}$." (CASA FÁCIL VAI FAVORECER..., 1990, p.5)
\end{abstract}

Após os primeiros meses de atendimento, o Jornal de Londrina, em artigo intitulado "Programa facilita casa própria para baixa renda", traz informações sobre a nova parceria das entidades conveniadas e informa quais os procedimentos para se ter acesso ao projeto. (MARCELINO JR., 1990, p.13)

A fase inicial do projeto foi desenvolvida na prefeitura, onde o usuário escolhia o projeto arquitetônico a partir de modelos prontos. Num segundo momento, o atendimento foi transferido para a sede do CREA-Londrina, onde a parceria com a Universidade Estadual de Londrina (UEL) foi implementada através da criação do Escritório Técnico de Engenharia e Arquitetura.

"A partir de amanhã, a Universidade Estadual de Londrina passa a oferecer mais um serviço à comunidade. Ontem foi inaugurado o Escritório Técnico de Engenharia e Arquitetura. (...) O escritório vai colaborar com o CREA no Projeto 'Casa Fácil' e vai prestar atendimento aos municípios de pequeno porte da região." (UEL OFERECE..., 1991, p.4)

Pode-se considerar o ano de 1993 um marco na história do Projeto Casa Fácil em Londrina, uma vez que este passou a personalizar o seu atendimento, indo de encontro à necessidade de cada usuário, ou seja, os projetos arquitetônicos não eram mais escolhidos dentre os modelos prontos, mas sim elaborados conforme a especificidade de cada caso.

Essa mudança só foi possível quando o projeto pôde contar com a participação de professores e estagiários da UEL e com a parceria estabelecida com o Departamento de Arquitetura do Centro de Estudos Superiores de Londrina (CESULON), através de seus professores e estagiários. Cabe ressaltar que Londrina é o único município do Paraná onde o projeto arquitetônico é personalizado.

Em 1994, após ter ampliado os serviços no município, o projeto foi transferido para as instalações do Centro 
Integrado de Vivência e Assistência à Criança e ao Adolescente - Cidade da Criança, espaço cedido pela Secretaria de Ação Social do município.

No mesmo ano, iniciaram-se as entrevistas de caráter seletivo com os usuários, com o objetivo de conhecer melhor a população atendida. As informações obtidas possibilitaram traçar o perfil dos usuários. Caso houvesse interesse por parte do entrevistado, as obras tinham acompanhamento dos estagiários, e estes eram supervisionados pelos professores através de um projeto de extensão desenvolvido pelo Departamento de Engenharia da UEL.

De agosto a dezembro de 1994 o atendimento foi suspenso devido à insuficiência de recursos financeiros. Até aquele momento o projeto era inteiramente subsidiado pelo repasse dos valores das Anotações de Responsabilidade Técnica (ART), emitidas pelo projeto para a entidade executora.

Em conseqüência do aumento da demanda, a arrecadação tornou-se insatisfatória, fazendo necessária a participação financeira dos outros órgãos envolvidos.

No final de outubro de 1994, a Folha de Londrina publica matéria mostrando a real situação do Projeto Casa Fácil naquele momento. De acordo com o jornal,

"O Projeto Casa Fácil desenvolvido pelo CREA (Conselho de Engenharia e Arquitetura) do Paraná, está suspenso em Londrina há pouco mais de 30 dias. $\mathrm{O}$ motivo para a finalização do programa na cidade foi a falta de acordo entre a Prefeitura e o Clube de Engenharia e Arquitetura de Londrina, que se responsabilizava pelos projetos e acompanhamento das obras." (FALTA DE ACORDO..., 1994, p.3)

Após longo período de negociações entre o Clube de Engenharia e Arquitetura e a prefeitura, o projeto foi reativado mediante assinatura de novo termo de cooperação, que definia recursos físico-financeiros.

A partir da reativação foram estabelecidas parcerias com a Companhia de Habitação de Londrina (COHAB-LD), que passou a ceder espaço para o atendimento, e com o Serviço de Comunicações Telefônicas de Londrina (SERCOMTEL), que ficou responsável pelo repasse financeiro, por se tratar de uma autarquia da prefeitura. (cf. PROJETO CASA FÁCIL..., 1995, p.3)

\subsection{Caracterização do Projeto Casa Fácil}

O executor do Projeto Casa Fácil em Londrina é o Clube de Engenharia e Arquitetura de Londrina, que tem desenvolvido suas ações em convênio com o CREA-PR, Prefeitura de Londrina, UEL, CESULON, COHAB-LD e SERCOMTEL.

O objetivo é atender famílias que tenham renda mensal até três salários mínimos regionais e que possuam um único imóvel, oferecendo ao usuário um projeto arquitetônico de até $70 \mathrm{~m}^{2}$ - que pode ser de construção ou ampliação (caso não ultrapasse a medida).

Os usuários podem escolher entre os projetos prontos ou personalizados, desenvolvidos pelos estagiários dos cursos de Engenharia e Arquitetura. Dessa forma, a opção fica a critério das famúlias.

Outros benefícios são oferecidos aos usuários: orientação técnica; isenção da taxa da ART — com a qual poderá obter o alvará, o laudo de vistoria de conclusão da obra e o Habite-se junto à prefeitura; matrícula da obra junto ao INSS (que também concede isenção de taxas para moradias de padrão popular); e condição de averbar a moradia no cartório de registros.

O projeto não beneficia só os usuários, mas todos os envolvidos na sua execução: a prefeitura, que passa a ter mais imóveis cadastrados no município, o que reduz as edificações clandestinas (aumentando, assim, a arrecadação do Imposto Predial e Territorial Urbano-IPTU); a UEL e o CESULON, prestando um serviço de alto alcance social, proporcionam aos alunos de Engenharia e Arquitetura, através dos estágios, experiência no atendimento ao público, na elaboração dos projetos e orçamentos e no acompanhamento da execução da obra.

Cabe ao Clube de Engenharia a coordenação geral do projeto, efetivando-se cada vez mais enquanto colaborador de importantes serviços à comunidade.

\section{ANÁLISE DO DESENVOLVIMEN- TO E RESULTADOS DO PROJETO CASA FÁCIL}

As condições econômicas ditadas pela conjuntura globalizante do capitalismo criaram um contexto propício para o surgimento de uma perspectiva que assegura à sociedade civil organizada canais de participação popular descentralizadores, onde passou a assumir novos papéis na formulação e gestão de políticas públicas alternativas.

O Projeto Casa Fácil, através do Clube de Engenharia e em parceria com outras instituições conveniadas, presta serviços de natureza pública no atendimento à população de baixa renda.

As implicações e os resultados ${ }^{3}$ de sua atuação no setor habitacional foram analisados a partir de informações baseadas em três indicadores: usuários (perfil da renda, experiência habitacional, situação de moradia na época e significado da casa própria); a construção da casa e o terreno (área pretendida e tamanho da família, construtor da obra, localização dos bairros e legalização do terreno); e o projeto arquitetônico (número de projetos, área construída, Habite-se e entidade responsável pelo projeto na opinião dos usuários).

Com relação ao primeiro item, verificou-se que um dos requisitos para o acesso ao Projeto Casa Fácil era o limite de até três salários mínimos mensais na composição da renda familiar, o que difere da política habitacional do governo, que estabelece como critério a comprovação mínima de três salários, o que limita o atendimento da demanda.

$\mathrm{O}$ projeto significa para os excluídos do $\mathrm{SFH}$ uma possibilidade real de construção da casa, uma vez que o direito à moradia não é restringido por critérios econômicos. 
Na análise, tornou-se relevante a experiência habitacional vivida pelos usuários, pois permitiu traçar o perfil das pessoas que procuram o projeto. Devido ao grande número de categorias criadas (78), foram selecionadas somente as que apresentaram os maiores índices. Dos 456 usuários entrevistados, 110 sempre pagaram aluguel, 100 nunca tinham pago aluguel, 25 pagavam aluguel e passaram a morar em casa cedida, 20 sempre moraram em casa cedida, 13 moravam em casa cedida e passaram a pagar aluguel, 24 moravam na casa dos pais e depois que casaram passaram a pagar aluguel e 20 entrevistados moravam na zona rural e depois de mudar para a cidade passaram a pagar aluguel.

Como se percebe, são muitas as experiências habitacionais, o que significa que quase todos os entrevistados passaram por situações difíceis e instáveis.

$\mathrm{Na}$ análise das condições de moradia dos usuários do projeto foram encontradas as seguinte categorias: alugada, cedida, própria e financiada. Os dados obtidos indicaram que $40 \%$ dos usuários moravam em casa alugada, $35 \%$ em casas cedidas, $20 \%$ já eram proprietários e desejavam aumentar a área construída e 5\% eram mutuários da COHAB-LD que, em razão de um convênio desta com o projeto, tinham a possibilidade de aumentar a área já existente.

Diante da constatação do alto índice de casas alugadas e de casas cedidas, é possível justificar o grande número de atendimentos realizados pelo projeto, confirmando, assim, a real necessidade da demanda atendida.

De acordo com os dados levantados, foram várias as razões de ordem simbólica ou econômica que demonstraram a aspiração pela casa própria. Entre as categorias citadas pelos usuários para classificar sua importância, destacam-se: livrar-se do aluguel $(19,08 \%)$; segurança $(17,32 \%)$; sonho da vida $(14,47 \%)$; tudo na vida $(13,60 \%)$; tranqüilidade $(9,21 \%)$; liberdade $(7,24 \%)$; conquista $(3,51 \%)$; estabilidade $(2,19 \%)$; bênção $(0,44 \%)$; melhoria de vida $(0,22 \%)$. Ao se estabelecer um paralelo com as experiências habitacionais, compreende-se melhor o significado atribuído pelos usuários à casa própria.

A existência de cadastro na COHAB-LD por parte dos usuários ilustra o grau de satisfação com a companhia e também identifica os motivos que os levaram a procurar o Projeto Casa Fácil. Dos 456 entrevistados, 65\% não possuíam cadastro. Destes, 302 procuraram o projeto porque não se identificaram com as normas propostas pela $\mathrm{COHAB}$ ou porque não foram aceitos por essa instituição. Esse dado confirma a discussão feita anteriormente sobre a política habitacional do país, pois revela o descontentamento com o sistema adotado pelas Companhias de Habitação.

No segundo item, verificou-se que o cruzamento feito entre a área de construção pretendida e o número de componentes das famílias atendidas é um dado importante para a verificação da eficácia do projeto, tendo em vista que a área construída da casa popular gira em torno de $36 \mathrm{~m}^{2}$ e que o número de residentes por unidade habitacional é de quatro a cinco pessoas. Isso significa que o usuário conta com mais espaço, conforto e privacidade, uma vez que o projeto oferece até $70 \mathrm{~m}^{2}$.

Considerando que uma construção residencial de até $70 \mathrm{~m}^{2}$ não se enquadra, para efeitos legais, como obra de engenharia, o usuário fica desobrigado de contratar um responsável técnico, podendo receber toda orientação através das associações de engenheiros e arquitetos, como mostram os dados coletados expostos na Tabela 1.

TABELA 1 - Executor da obra por desejo de acompanhamento profissional

\begin{tabular}{lccc}
\hline $\begin{array}{l}\text { Executor } \\
\text { da obra }\end{array}$ & Total & \multicolumn{2}{c}{$\begin{array}{c}\text { Deseja acompanhamento } \\
\text { profissional }\end{array}$} \\
\hline & & SIM & NãO \\
\hline Ainda não tinha & 21,94 & 11,33 & 10,61 \\
Mutirão Familiar & 39,47 & 21,80 & 17,67 \\
Pedreiro contratado & 14,25 & 9,06 & 5,19 \\
Proprietário & 24,34 & 9,02 & 15,32 \\
\hline Total & $\mathbf{1 0 0 , 0 0}$ & $\mathbf{5 1 , 2 1}$ & $\mathbf{4 8 , 7 9}$ \\
\hline
\end{tabular}

Fonte: CAMPONEZ (1996).

A maioria dos usuários não tinha condições de arcar com as despesas da construção da casa. Desta forma, a autoconstrução era a maneira comumente encontrada para a solução do problema.

Quanto à localização, é relevante destacar que dos 180 bairros citados, 68 usuários, ou seja, 14,91\%, iam permanecer no mesmo bairro, continuando num ambiente conhecido, onde, muitas vezes, encontra-se grande parte de seus familiares.

Em relação à situação legal dos terrenos, obteve-se as seguintes categorias: pagos, financiados e cedidos pela prefeitura. A situação do terreno quanto à escrituração mostrou que a grande maioria tinha como único documento de garantia o contrato de compra e venda. O usuário só consegue registrar o imóvel em cartório após o período de construção, em razão da situação financeira.

Finalmente, os resultados do terceiro indicador mostraram quantos projetos foram aprovados, quantos metros de área foram construídos e quantos pedidos de Habite-se foram solicitados nos cinco primeiros anos do projeto (1990 a 1995).

TABELA 2: Número de projetos, área construída $\left(\mathrm{m}^{2}\right)$ e Habite-se (1990-1995)

\begin{tabular}{lcccc}
\hline Ano & $\begin{array}{c}\mathbf{N}^{\circ} \text { de } \\
\text { projetos }\end{array}$ & $\begin{array}{c}\text { Área } \\
\text { construída }\end{array}$ & Habite-se & $\begin{array}{c}\text { \% Habite-se/ } \\
\text { projetos }\end{array}$ \\
\hline 1990 & 292 & 15.312 & 72 & 24,66 \\
1991 & 396 & 21.797 & 80 & 20,20 \\
1992 & 400 & 34.396 & 70 & 17,50 \\
1993 & 653 & 38.116 & 70 & 10,72 \\
1994 & 383 & 21.107 & 28 & 7,31 \\
1995 & 546 & 31.373 & 10 & 1,83 \\
\hline Total & $\mathbf{2 . 6 7 0}$ & $\mathbf{1 6 2 . 1 0 1}$ & $\mathbf{3 3 0}$ & \\
\hline
\end{tabular}

Fonte: CAMPONEZ (1996).

A pesquisa constatou que havia um equívoco por parte dos usuários sobre o reconhecimento da responsabilidade do Projeto Casa Fácil. Os dados mostraram que tanto a prefeitura como a COHAB-LD apareciam como responsáveis na sua concepção. 
Por se tratar de um convênio entre várias entidades, os usuários confundiam ou desconheciam o verdadeiro responsável pelo gerenciamento do projeto, sendo informados corretamente somente na triagem seletiva. A imagem da prefeitura como a executora do projeto é favorável politicamente à gestão administrativa, uma vez que a promove enquanto prestadora de mais um serviço à comunidade. No entanto, o mentor do projeto é o CREA-Curitiba, e os responsáveis pelo acompanhamento e desenvolvimento são as entidades de classe, nesse caso o Clube de Engenharia.

\section{CONCLUSÃO}

As mudanças ocorridas nos anos 90, particularmente no campo das políticas públicas, têm transformado as relações entre Estado e sociedade civil no país, resultando na redefinição dos papéis por estes representados.

Dessa maneira, tem-se vários setores da sociedade civil atuando junto a programas de competência do Estado. O Projeto Casa Fácil - Convênio de Moradia Popular é um exemplo desta nova tendência.

Com o estudo dessa experiência buscou-se verificar de que forma se estabelece a parceria dos dois pólos envolvidos, Estado e sociedade civil, pois o projeto desenvolve-se com a participação do setor privado e do poder público local.

Ao se estabelecer um paralelo entre o órgão governamental gestor da habitação no município e o Projeto Casa Fácil, chega-se aos seguintes resultados:

O projeto amplia o espaço de participação do acesso à casa própria, pois surge como alternativa para os excluídos em virtude da renda pelo $\mathrm{SHF}$, tornando-se o responsável direto por um grande número de projetos e de área construída na cidade, fator que altera a configuração do cenário urbano em Londrina. A metragem oferecida pelo projeto $\left(70 \mathrm{~m}^{2}\right)$, embora limitada, constitui-se numa vantagem para o usuário, pois é praticamente o dobro da área construída pelas Companhias de Habitação.

De acordo com os dados obtidos, pôde-se verificar um grande desinteresse da população $(40,7 \%$ dos entrevistados) em procurar o sistema de financiamento oficial, e descobriu-se que $32,9 \%$ dos que procuraram esse sistema não foram contemplados.

O projeto possibilita a muitos usuários continuar vivendo no bairro onde mora (como ocorria com $14,91 \%$ dos casos pesquisados - dado que poderia representar um percentual ainda maior se os bairros próximos fossem considerados). É importante ressaltar que a manutenção da proximidade entre o local de origem e o local escolhido para a construção possibilita a preservação de suas relações sociais, ao contrário do que ocorre nos programas oficiais, que, na maioria das vezes, constroem conjuntos habitacionais em locais distantes e desconhecidos.

A população de baixa renda geralmente só adquire casa própria se passar, basicamente, por dois caminhos: financiando-a ou comprando um terreno para construir.

Como já discutido anteriormente, a maioria da população carente não consegue ser contemplada com a primeira alternativa. Por outro lado, comprar um terreno implica em privações financeiras, o que limita novamente o acesso à casa própria. Há, dessa maneira, uma grande parcela que não chega sequer a adquirir o terreno.

O Projeto Casa Fácil também não atinge esta faixa da população, pois se propõe elaborar projetos arquitetônicos dentro das normas obrigatórias e dar acompanhamento técnico. Isso significa que ainda há uma parcela considerável que permanece completamente ignorada.

Somente os que possuem terreno podem ser atendidos pelo projeto e, caso a construção já tenha sido iniciada, o interessado perde o direito. Sendo assim, o Projeto Casa Fácil se apresenta como uma alternativa à regularização das habitações na cidade, contribuindo com a diminuição do percentual de habitações clandestinas.

Ao dar início a esse tipo de programa, o CREA muda, de certa forma, a maneira como o Estado controla a produção do espaço habitado, alterando, mesmo que sutilmente, a lógica do processo de acumulação e especulação imobiliária.

A pesquisa que originou este artigo mostrou que o Projeto Casa Fácil abre uma nova possibilidade entre as alternativas até então existentes. Isto pode ser afirmado pela demanda social atendida e pela quantidade de projetos arquitetônicos aprovados.

Embora se trate de um projeto de apoio técnico, sem pretensões de financiamento da obra, o Projeto Casa Fácil traz a possibilidade de acesso ao exercício da cidadania, expresso aqui pelo direito à moradia, pois está mais próximo dos anseios e necessidades da população.

É importante ressaltar que o projeto foi implantado por uma entidade de classe, à qual não compete o papel de atender toda demanda advinda da defasagem da política habitacional, mas que, considerando a necessidade de formas participativas cidadãs, insere-se no espaço da prestação de serviço.

Cabe colocar que não se pretendeu, aqui, pensar esta nova relação somente como resultante da crise estatal dos últimos anos, mas, também, sob a ótica do desenvolvimento e dos avanços da sociedade civil enquanto colaboradora e, às vezes, gestora de política social. Este novo papel desempenhado pela sociedade civil denota um caráter mais amplo de busca de cidadania no processo de democratização no Brasil.

\section{NOTAS}

1 O Estado é entendido aqui como o "campo da política institucional: do governo, dos partidos e dos aparelhos burocráticos de dominação"; e sociedade civil é "o campo da organização social que se realiza a partir das classes sociais ou de todas as outras espécies de agrupamentos sociais fora do Estado enquanto aparelho". (WARREN, 1993, p.50)

2 Entende-se por setor privado tanto o seguimento empresarial como entidades sem fins lucrativos e associações da população usuária desses serviços. (cf. FARAH, 1990, p.11)

${ }^{3}$ Os dados sobre o Projeto Casa Fácil foram aqui descritos de forma genérica. Para informações mais completas ver CAMPONEZ (1996). 


\section{REFERÊNCIAS BIBLIOGRÁFICAS}

BLAY, Eva. Eu não tenho onde morar: vilas operárias na cidade de São Paulo. São Paulo: Nobel, 1985.

CAMPONEZ, Adriana A. Política habitacional: as novas relações entre Estado e sociedade civil. Londrina, 1996. Monografia (Especialização em Sociologia e Sociologia da Educação) - Universidade Estadual de Londrina.

CASA FÁCIL VAI FAVORECER população de baixa renda. Folha de Londrina, 15 jul.1990, p.5.

CASTRO, Maria Helena. "Descentralização e política social no Brasil: as perspectivas dos anos 90". Espaço e Debates, v.11, n.32, jan.1991.

CREA-PR-CONSELHO REGIONAL DE ENGENHARIA E ARQUITETURA DO PARANÁ. Casa facil. Projeto Moradia Popular. Curitiba: CREA-PR, 1995.

DRAIBE, Sônia M. "Por uma nova política social - questões de prioridades, gestão e administração de programas básicos”. São Paulo em Perspectiva, v.3 n.1-2, jan./jun. 1989.

ENGELS, F. A questão da habitação. Belo Horizonte: Aldeia Global, 1979.

FALTA DE ACORDO suspende projeto casa fácil do CREA. Folha de Londrina. Folha Paraná, Londrina, 25 out.1994, p.3.

FARAH, Marta F.S. "Público e privado na provisão de habitações nos países centrais". Espaço e Debates, v.10, n.31, jul.1990.

GOHN, Maria da G. "Cidades, ONGs e ações coletivas: novas parcerias, atores e práticas civil". São Paulo em Perspectiva. Questões Urbanas, o Sentido da Mudança, v.9, n.2, abr.jjun. 1995.

MNLM-PLATAFORMA NACIONALDA HABITAÇÃO POPULAR DO MOVIMENTO NACIONAL DE LUTA POR MORADIA. Movimento Nacional de Luta por Moradia. [s.l.]: [mimeo], 1994.

MARCELINO JR. "Programa facilita casa própria para baixa renda". Jornal de Londrina, 9 set. 1990, p.13.

MARICATO, Ermínia. Políica habitacional no regime militar: do milagre brasileiro à crise econômica. Petrópolis: Vozes, 1987.

PERUZZO, Dilvo. Habitação: controle e espoliação. São Paulo: Cortez, 1984.

PROJETO CASA FÁCIL começa a atender na COHAB. Folha de Londrina. Folha Paraná. Londrina, 17 mar.1995, p.3.

UEL OFERECE serviços de arquitetura e engenharia. Jornal de Londrina, 27 out. 1991, p.4.

VALADARES, Lícia P. (org.). "Repensando a habitação no Brasil". Debates Urbanos 3. Rio de Janeiro, Zahar, 1983

VILLAÇA, Flávio. O que todo cidadão precisa saber sobre habitação. Cadernos de Educação Política, n.16, 1986.

WARREN, Mse. Redes de movimentos sociais. São Paulo: Loyola, 1993. 